Original Research Articles

\title{
A First-Class Ticket to the Planet Mars, Please
}

\author{
${ }^{1}$ Relly Victoria Petrescu, ${ }^{2}$ Raffaella Aversa, ${ }^{3}$ Bilal Akash, ${ }^{2}$ Antonio Apicella and \\ ${ }^{1}$ Florian Ion Tiberiu Petrescu \\ ${ }^{I}$ ARoTMM-IFToMM, Bucharest Polytechnic University, Bucharest, (CE), Romania \\ ${ }^{2}$ Department of Architecture and Industrial Design, Advanced Material Lab, \\ Second University of Naples, 81031 Aversa (CE), Italy \\ ${ }^{3}$ Dean of School of Graduate Studies and Research, American University of Ras Al Khaimah, UAE
}

Article history

Received: 07-11-2017

Revised: $17-11-2017$

Accepted: 27-11-2017

Corresponding Author: Florian Ion Tiberiu Petrescu ARoTMM-IFToMM,

Bucharest Polytechnic

University, Bucharest, (CE),

Romania

E-mail: scipub02@gmail.com
Abstract: The paper presents some aspects related to the current stage in the aerospace industry, referring to the current possibilities of moving in space. The main problem that has kept mankind for so many millennia has been the less speed of movement, but also the difficult exit into outer space. For a ship to be able to defeat gravitational forces and go out into outer space, leaving the planet and the earth's atmosphere and to place itself in orbit, the required minimum travel speed is about $28,476 \mathrm{~km} / \mathrm{h}$. In order to leave and the Earth orbit on which a ship is moving like a satellite, a ship needs a minimum speed of $40000 \mathrm{~km} / \mathrm{h}$. For a long time, such a speed was very difficult to achieve. Even with a huge amount of chemical fuel on board, a rocket had to throw a lot of rocket stages (modules) in an attempt to get out of the ground. Besides the huge fuel consumption (not to mention the huge pollution produced), the ship also encounters various technical difficulties, which most often cause it to abandon and return (the bathtub) and to the ground. The shuttle has attempted to modify something from this difficult start, coming out of the atmosphere, gradually planted, like a plane and not upright like a rocket. They, therefore, had the advantage of a lower mass, lower fuel consumption and resistance to advancing by making them more similar to planes. In addition, such a ship could emerge and return to the terrestrial space several times and not just as the missiles did. The shuttle was a step forward for humanity, even though it was still moving slowly. Then came the ions (gas) reactors for spatial ships, which managed to accelerate ships at increasing speeds. Of all spacecraft that were launched by humans, there were some that had an impressive speed. The current record is owned by the New Horizons mission to Pluto and the Kuiper belt. Launched in 2006 by NASA, the spacecraft had a speed of 58,536 kilometers per hour, but it has reached over 160,000 kilometers per hour on its route. For comparison, Voyager 1 currently has a speed of 61,200 kilometers per hour. Regarding pure heliocentric speed, speed recorders are the Helios I and II probes, which were launched in 1974 and 1976 and reached speeds of 252,000 kilometers per hour. The Juno mission to Jupiter will send a spacecraft that will reach the speed of over 250,000 kilometers per hour. And in 2018, a new NASA mission called Solar Probe Plus will launch a ship that will travel at an astonishing speed of 720,000 kilometers per hour. This would mean the probe could travel from Earth to the Moon in about half an hour and the Earth-Mars distance in about 10 days instead of five months.

Keywords: NASA, Moving in Space, Aerospace, Aeronautics, Energy

\section{Introduction}

The paper presents some aspects related to the current stage in the aerospace industry, referring to the current possibilities of moving in space.
The main problem that has kept mankind for so many millennia has been the less speed of movement, but also the difficult exit into outer space.

For a ship to be able to defeat gravitational forces and go out into outer space, leaving the planet and the earth's 
atmosphere and to place itself in orbit, the required minimum travel speed is about $28,476 \mathrm{~km} / \mathrm{h}$. In order to leave and the Earth orbit on which a ship is moving like a satellite, a ship needs a minimum speed of $40000 \mathrm{~km} / \mathrm{h}$.

For a long time, such a speed was very difficult to achieve. Even with a huge amount of chemical fuel on board, a rocket had to throw a lot of rocket stages (modules) in an attempt to get out of the ground. Besides the huge fuel consumption (not to mention the huge pollution produced), the ship also encounters various technical difficulties, which most often cause it to abandon and return (the bathtub) and to the ground. The shuttle has attempted to modify something from this difficult start, coming out of the atmosphere, gradually planted, like a plane and not upright like a rocket. They, therefore, had the advantage of a lower mass, lower fuel consumption and resistance to advancing by making them more similar to planes. In addition, such a ship could emerge and return to the terrestrial space several times and not just as the missiles did.

The shuttle was a step forward for humanity, even though it was still moving slowly.

Then came the ions (gas) reactors for spatial ships, which managed to accelerate ships at increasing speeds. Of all spacecraft that were launched by humans, there were some that had an impressive speed. The current record is owned by the New Horizons mission to Pluto and the Kuiper belt. Launched in 2006 by NASA, the spacecraft had a speed of 58,536 kilometers per hour, but it has reached over 160,000 kilometers per hour on its route. For comparison, Voyager 1 currently has a speed of 61,200 kilometers per hour. Regarding pure heliocentric speed, speed recorders are the Helios I and II probes, which were launched in 1974 and 1976 and reached speeds of 252,000 kilometers per hour. The Juno mission to Jupiter will send a spacecraft that will reach the speed of over 250,000 kilometers per hour.

And in 2018, a new NASA mission called Solar Probe Plus will launch a ship that will travel at an astonishing speed of 720,000 kilometers per hour. This would mean the probe could travel from Earth to the Moon in about half an hour and the Earth-Mars distance in about 10 days instead of five months (Aversa et al., 2017a-e; 2016a-o; Berto et al., 2016a-d; Mirsayar et al., 2017; Petrescu and Petrescu, 2016a-c; 2013a-d; 2012a-d; 2011a-b; Petrescu, 2016; 2012a-b; 2009; Petrescu and Calautit, 2016a-b; Petrescu et al., 2016a-c).

\section{Methods and Materials}

Spaceflight uses space technology to make spaceships fly into outer space. Spatial exploration (space observation, reconnaissance satellites and other Earth observation satellites), as well as commercial activities (satellite telecommunication and space tourism), are used in space exploration and space exploration.
A space flight is a flight of a flying body that takes place outside the Earth's atmosphere, that is, at least 36,000 feet above the terrestrial surface, where there is no air, the flying objects no longer encounter rubbing resistance. The boundary between air flights and space flights is located, according to the International Aeronautics Federation (FIA), at a height of about 100 $\mathrm{Km}$ above the Earth.

Only in the 20th century, when the rocket technology was born and developed, it became possible for such long-lasting accelerations to allow space flight and thus to leave Earth for longer. The theory of space flight was among others, by the Russian Constantin Tiolkovski (1857-1935) developed, who found the basic equation of the ascension of the missiles. Also, US engineer R.H. Goddard has already built small rocket engines since 1910 and in 1936 he has managed to launch a rocket with liquid fuel.

To reach a spatial orbit, an Earthly body must achieve, at Earth's speed, a high speed to overcome the friction of the air and the gravitational pull of the Earth. This speed, called the first cosmic speed, is $7.9 \mathrm{~km} / \mathrm{sec}$. or $28,476 \mathrm{~km} /$ hour. By this velocity, the centrifugal force of the flying body equals (compensates for) the gravitational force of the Earth.

Satellites fly to a height of at least 36,000 meters above the ground. A geostationary meteorological satellite remains "parked" in a terrestrial orbit above a point of the Earth (with very small deviations) because in $24 \mathrm{~h}$ it also rotates around its axis. Of course, not all satellites are geostationary ("fixed") and they can and scatter on variable spatial trajectories above land surface for different purposes.

If the velocity of a released body (satellite, etc.) becomes greater than the first cosmic velocity, then it follows an elongated, elliptical circle trajectory. In the case of the limit, when the furthest point of the elliptical orbit tends to infinity $(\infty)$, then the satellite does not remain on a closed, orbital trajectory and follows a parabolic trajectory continually departing from the home planet in the alien space. This is the "second cosmic speed". Concretely, in order to get out of the earthly (gravitational) sphere and to begin an interactive flight, a speed of $11.2 \mathrm{~km} / \mathrm{sec}$ is needed for Earth or $40,000 \mathrm{~km} / \mathrm{h}$.

Just below the "second speed" lies the so-called "escaping" speed through which a body (space probe) left on Earth can come out of the terrestrial "attraction," but it still remains in the solar system of Sun's attraction, as an artificial planetoid. It is possible to route radio signals to a space probe, commanding small propulsion engines on board so that it can be oriented towards one or other of the planets of the solar system.

The first flight to a terrestrial spatial orbit was made by the Soviet satellite "Sputnik" on October 14, 1957 and the first human flight was to cosmonaut Yuri Gagarin in April 1961. The first flight to the moon of a 
human crew was to the Americans astronauts Armstrong, Aldrin and Collins on July 16, 1969. Armstrong and Aldrin moored on July 20, 1969, with the Eagle selennial module, while Collins piloted the Columbia Command module that was orbit the Moon.

Many of the spacecraft are called missiles (cosmic). The only part of a cosmic rocket that returns to Earth is known as a space capsule, which includes command, control and measurement equipment (including flight data and recorded research data) and astronauts for crewed spacecraft human. Capsules should be provided in different ways against overheating when reintroduced into the earth's atmosphere. The propulsion (force) required to reach the launching speeds is achieved by rocket motors of the type reactive, i.e., engines in which the fuel (liquid or solid) burns at an impressive speed with the help of oxidants, at a constant pressure of $20 \div$ 40 ATM. and temperatures above $3,000^{\circ} \mathrm{C}$, huge amounts of propulsion gas coming out, strongly accelerated by nozzles located behind the rocket's body, causing the missile to move in the other direction. There are several such diures and by their control, it is possible to orientate and equilibrate the cosmic missile. To ease the launch of missiles, they are built with several stages of fuel that are abandoned after the fuel has been exhausted. Fuel stored in liquid form is easier to control and longer than solid ones.

Interstellar travel or interstellar flight is a journey with or without human crew that takes place between stars. The concept of interstellar travel by spacecraft is a common theme in science fiction. Interstellar travel is conceptually far more difficult than the interplanetary journey that takes place between the planets of the same star system. The intergalactic journey (i.e., the journey between different galaxies) would be much more difficult than interstellar.

Many scientific papers have been published in connection with these concepts. Taking into account the necessary travel time and engineering, both unmanned and in-flight interstellar travel seem possible, although both pose considerable technological and economic challenges, so mankind is unlikely to launch such spacecraft in the near future, especially those with a human crew. NASA, ESA and other space agencies have been involved in research on these flights for many years and have reached a number of theoretical approaches.

The need for energy seems to make the interstellar journey for one-generation ships impractical, making it more secure to carry a crewed journey in a suspended condition in shrouded shielded ships from interstellar dangers.

The main challenge faced by making an interstellar journey is the huge distance to go. This means that you need a very high speed and / or a very long travel time. The required travel time with most realistic propulsion methods would be from decades to millennia. Therefore, an interstellar ship would be more severely exposed to the dangers of interplanetary journeys, dangers such as vacuum, radiation, imponderability and micrometeorites. The long journey time makes it difficult to design human missions. The fundamental limits of space-time will be another challenge. In addition, it is difficult to foresee the justification of interstellar journeys for conventional economic reasons.

An important factor that increases the difficulty of designing this trip is the energy that needs to be provided to get a reasonable travel time. A lower limit for the required energy is the kinetic energy $K=1 / 2 \mathrm{mv} 2$ where $\mathrm{m}$ is the final mass. If there is a need for deceleration on arrival and this cannot be achieved by other means than with the engines of the ship, then the required energy will be at least twice as the energy required to stop the ship is equal to the energy required to accelerate at travel speed.

The speed of travel of a space crewed spacecraft to take place only a few decades to the nearest star should be thousands of times higher than the speed of current spacecraft. This means that energy is needed millions of times greater than the current energy used. Acceleration of one tonne to one-tenth of the light speed requires at least $450 \mathrm{PJ}$ or $4.5 \times 1017 \mathrm{~J}$ or 125 billion $\mathrm{kWh}$, without taking account of losses. This energy has to be transported along the journey (fuel) because the solar panel's method does not work at enormous distances from the Sun or other stars.

There are opinions that the magnitude of this energy would make the interstellar journey impossible. These beliefs were presented at the 2008 Conference on Propulsion Methods, a conference at which future spacerelated challenges were discussed and debated. It has come to the conclusion that it is unlikely to say whether people could ever explore beyond the limits of the Solar System. Brice N. Cassenti, an associate professor at the Department of Engineering and Science of the Rensselaer Polytechnic Institute, said: "At least 100 times the total energy produced worldwide, (in a given year) would be required for a trip (to Alpha Centauri) ".

Astronomical distances are often measured during the time required for a beam of light to travel between two points (see an-light). Light travels through the cosmic vacuum with about 300,000 kilometers per second or 186,000 miles per second.

The Earth-to-Moon distance is only 1.3 seconds light. With the current propulsion technologies of a spacecraft, a ship can travel from Earth to Moon in about eight hours (New Horizons). This means that light travels approximately 30,000 times faster than the current propulsion technologies of spacecraft. The distance from Earth to other planets in the solar system varies from three light-minutes to about four light-hours. Depending on the planet and its alignment with the Earth, an unmanned spacecraft will travel these distances from the solar system from a few months to a little over a decade. 
The closest star known by the Sun is Proxima Centauri, which is 4.23 light-years away. However, there may be undiscovered systems of gray dwarf stars. The fastest spacecraft created by humans, Voyager 1, traveled to $1 / 600$ part of a light year in 30 years and now has reached 1/18,000 of the speed of light. At this rate, a trip to Proxima Centauri would take 72,000 years. Of course, Voyager 1 was not designed specifically to travel fast to the stars and with the current technology, such a trip would take less. Travel time could be reduced to several millennia using space sailboats; or just a century or less using nuclear-powered propulsion. For a better understanding of the giant distance to one of the closest suns, Alpha Centauri A (a sun-like star), the Sun-Earth distance (which is $\sim 150,000,000 \mathrm{~km}$ ) is one meter long. At this scale the distance to Alpha Centauri A would be $271 \mathrm{~km}$ or about 169 miles.

A major problem in traveling at extremely high speeds is that interstellar matter (dust and gas) can cause considerable damage to the ship due to its relatively high speeds and large kinetic energies involved. Some shielding methods have been proposed to alleviate these issues. Larger objects (such as macroscopic pieces of dust) are far less common, but the impact with them would be much more destructive. Risks to the impact with these objects and methods of mitigating these risks have not been properly assessed.

Turn-back delay time is the minimum time between observation by a probe and the moment the probe can receive instructions from Earth regarding the reaction to the observation. Given that the information cannot travel faster than the speed of light, up to Voyager 1 communications are currently about $32 \mathrm{~h}$ and near Proxima Centauri would be 8 years old. Faster reactions can be obtained by scheduling the probes to make decisions automatically based on the observations made. It is not the case if the flight is human crew because it can respond immediately to the observations received. However, the turn-around delay time makes the mission, in terms of communication, highly isolated from the Earth (just as they were previously isolated on Earth by human explorers before the invention of the electric telegraph).

Interstellar communication is still problematic - even if a probe could reach the nearest star, its ability to communicate back to Earth would be difficult given the extreme distance.

The mass of any ship capable of transporting people would inevitably be much greater than that of unmanned interstellar probes. For example, the first Space Sputnik 1 spacecraft had a payload of $83.6 \mathrm{~kg}$, while the first spacecraft carrying a living passenger (Laika Dog), Sputnik 2, had a payload of six times large, $508.3 \mathrm{~kg}$. This difference increases enormously in interstellar missions, given the very long time and need resulting from a closed life support system. As technology continues to move forward, given the risks and requirements needed to achieve the human crew's interstellar journey, it is unlikely that the first interstellar missions will carry on board earthly life forms.

If a spacecraft could travel on average by 10 percent of the speed of light (and would decelerate on arrival in human crew missions), that would be enough to reach Proxima Centauri in forty years. Some propulsion concepts have been proposed. These could eventually be developed somewhere in the future, but none of these concepts can be achieved in the short term (in a few decades) at an acceptable cost.

Slow interstellar travel projects, such as the Longshot project, are generally based on propulsion techniques that can be built in the near future. Consequently, the journey time is extremely long, from about a century to several millennia. These trips would be simple to accomplish and could be used to colonize space. The necessary propulsion systems are simpler than those necessary for fast interstellar travel, but the journey is a huge obstacle in itself. Here are the main solutions for this scenario: ship-generation, suspended animation, prolongation of human life, transport of frozen human embryos. If technological progress does not allow for fast interstellar travel, a millennium journey for survival would be acceptable to the life of a smart race that would be millions of years.

The ability to develop ships capable of getting faster to other stars, that is, during a human life, is naturally much more attractive. However, this would require much more advanced propulsion methods or a different physics.

In 1957, it was considered possible to construct an 8 million-tonne spacecraft with nuclear-powered propulsion engines capable of reaching $7 \%$ of the speed of light. The problem with this method is that it uses nuclear explosions for propulsion and therefore includes high radiation risks.

Another theoretical method was that proposed in 1960 by Robert W. Bussard, called the Bussard collector or statoreact, in which a kind of huge cup would capture and compress the interstellar hydrogen that would have been used in a nuclear fusion reaction and then - Expel the resulting helium. Because the fuel would be gradually collected during the voyage, the ship could theoretically accelerate up to the speed of light. In the years to come, the proposal has been the subject of calculations that have estimated that the traction force generated is less than the resistance caused by the shape of the gallery. Finally, a gyroscope-stabilized reactor was designed to allow the traction force to overcome resistance.

\section{Results}

The Orion project was a study of a spacecraft to be propelled directly by a series of atom bomb explosions 
behind the ship (nuclear pulse propulsion). Initial versions of this vehicle have been proposed for launch from the ground, with significant decreases in radioactive nuclear waste; in the latest most recent versions have been developed to be used only in outer space.

Teleportation is a process of moving an object from one place to another, more or less instantaneously, without the object going through the space between the two positions. Several methods of teleportation (spacetime holes, wormholes) have been theoretically invented, but experimentally only quantum and psychic teleportation have been confirmed.

At present, "exact" quantum teleportation is only possible for photons and atoms. Inaccurate teleportation (where the quantum state is not preserved) is possible by encoding the object information, transmitting this information to another location, for example by radio or another method and creating a copy of the original object in a new place. Teleportation is also proposed as an explanation for many abnormal phenomena and is commonly used in SF literature.

In antiquity, other words were used to describe phenomena similar to what we today call teleportation, e.g., "bilocation," when it is said that a body occupies two different places simultaneously. The term "teleportation" (which extends the term proposed by Charles Fort) was first used by Derek Parfit as part of his imaginary experiment.

The term "teleportation" was introduced in the early 1900 s by the American writer Charles Fort to describe the strange disappearances and anomalies that, according to his thought, were related to teleportation. He has joined the Greek tele- term (meaning "far") with the Latin porting term (meaning "to carry", "lead"). For the first time, the term was used by Fort in the second paragraph of his book "Lo!". 1931 - "In this book, I have noted that there are indications of the existence of a transporting force called Teleportation." So, halfheartedly, half seriously, Fort added, "I can be accused of assembling lies and superstitions. To some extent, yes and no, I give you the description." Fort suggests that teleportation can explain different paranormal phenomena. It's hard to say, if Fort considers its own "serious" theory, it can only see a way to explain strange phenomena that official science could not explain (Teleportare, De la Wikipedia).

Until recently, physicists could teleport only light or atoms at short distances (millimeters). But now things have changed since publishing in the October 2006 scientific journal Nature (Sherson et al., 2006), where Professor Eugene Polzik and his command from the Niels Bohr Institute at Copenhagen University, Denmark, made a great leap in studying teleportation (Science \& Space, 2006). In the experiment, information from a weak light beam was teleported to a macroscopic object containing thousands of billions of atoms, half a meter away from each other. This technology uses quantum inseparability and quantum measurements.

There are several hypothetical methods of transporting matter from one place to another without physically moving in space between them. Some of the methods are seriously studied by physicists, while others exist only in fantasy.

One method proposes teleportation as a transmission of information, which is used to accurately rebuild the object or body at the destination. The use of this method of transporting people for transport has many technical and moral obstacles, such as how to scan the human body, especially the brain, with sufficient precision and recreate it. There is a problem if, during scanning, the human body is destroyed and its copy is recreated, can it continue life normally? Is it possible to copy the human mind (soul)?

Those who believe in supernatural can deny copying and recreating the soul and will consider this method dirty. But there are other methods of teleportation where the human body is teleported whole without scanning and recreation. The method is called teleportation through holes in space-time. The body is thrown out of the Universe, after returning to the real universe, because matter can't exist outside the real universe. Because the object has disappeared from one place and appeared in another without being in the space between them, this move can be called teleportation because it satisfies the definition of teleportation.

It is not clear if the duplication of a person requires exact reproduction of his quantum state with quantum teleportation that destroys the original, or macroscopic measurements are sufficient. In the non-destructive version, any act of teleportation creates a new copy of the person. Such technology would have applications like virtual medicine, where manipulation of data stored in the machine could make a difference in the physical data of the person.

Dimensional teleportation is a method, often described in fantastic stories and comic books. The method involves the existence of several Universes, where the object can rejoin another place in the Universe. This method is not taken seriously by the scientific community because it is thought that the physical movement of objects is not possible between different Universes.

Another form of teleportation used in science fiction and described in the Terminator series of films, The Fly (1986), Star Trek, etc. Send the object through Wormhole or similar phenomena at a speed higher than the speed of light, without problems with Werner Heisenberg's uncertainty or signal interference. Both forms of teleportation described above are known as "Movements" or "Topological Tunnels" (Scientific American).

These methods of teleportation eliminate many shortcomings, not supported by religion and philosophy, 
since the original body remains intact in teleportation and can continue its existence.

Mental teleportation by mental power by people is called p-teleportation, "psychopointing" or "jaunting"; named after the fantastic writer (Jaunte) who discovered this way in The Stars My Destination (originally called Tiger! Tiger!), a fantastic story by Alfred Bester. This type of teleportation enters the paranormal domain.

In religious and occult literature, teleportation is an instant movement of people from one place to another, with supernatural miracles or psychic force, but not with technological methods.

In June 2002, Doctor Warwick Bowen and Dr. Ping Koy Lam, Professor Hans Bachor and Dr. Timothy Ralph of the Australian National University conducted quantum teleportation of a laser beam (The Sydney Morning Herald, 2006).

It was a successful quantum teleportation experiment with the use of coupled photons. The photon to be teleported was scanned and its quantum properties copied to a replacement photon. Then the original photon was recreated in another place, at an arbitrary distance, proving the theorems proposed by Einstein to explain "strange remote actions."

Numerous physicists from Innsbruck University and the National Institute of Standards and Technology worked independently to beam calcium and beryllium ions in 2004. Two groups used different techniques but obtained similar results following the same basic protocol (Rincon, 2004).

In October 2006, Eugene Polzik and his team at the Niels Bohr Institute of the University of Copenhagen, Denmark, carried out a teleportation experiment on a microscopic atomic microscopic object at a distance of half a meter. "For the first time, there was the teleportation between light and matter, two different objects." (The Sydney Morning Herald, 2006).

\section{Space-Time Distortion}

According to the theory of general relativity, spacetime is curved. In science fiction, one can imagine using a "shortcut" between two points. The following formula based on general relativity can allow faster travel than light if space-time is curved.

In 2012, NASA physicist Harold White revealed that he and his team are working on the design of a spacecraft to travel at a speed higher than that of light.

Now, White has worked with an artist to create a new and more realistic design of the ship, writes Gizmodo.

In order to reach such speeds, the ship should have strong propulsion like ion or plasma. These propulsion systems have been called SF warp units.

A spacecraft equipped with a "warp" unit would allow moving at higher speeds than light by "bending" the space around it, thus reducing distances (Fig. 1).

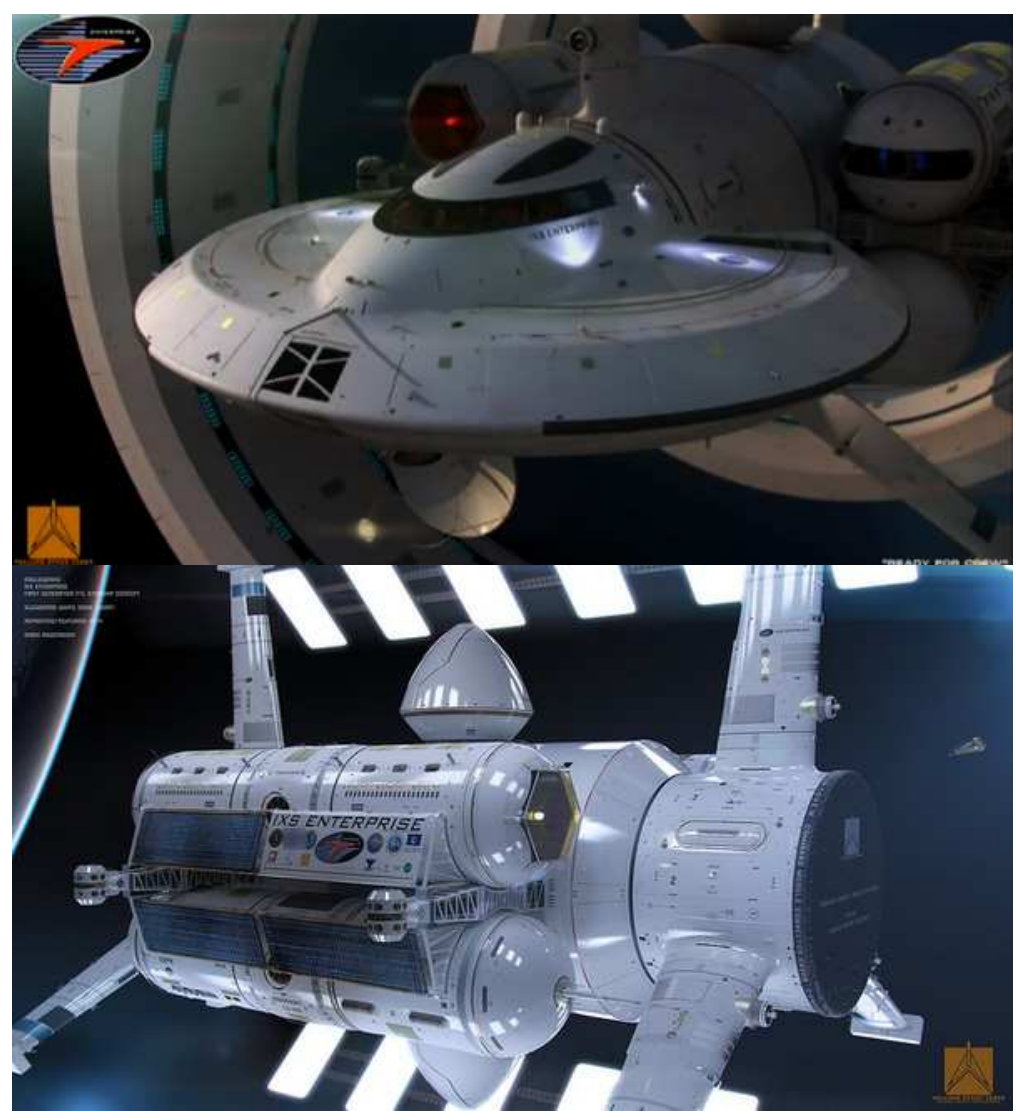




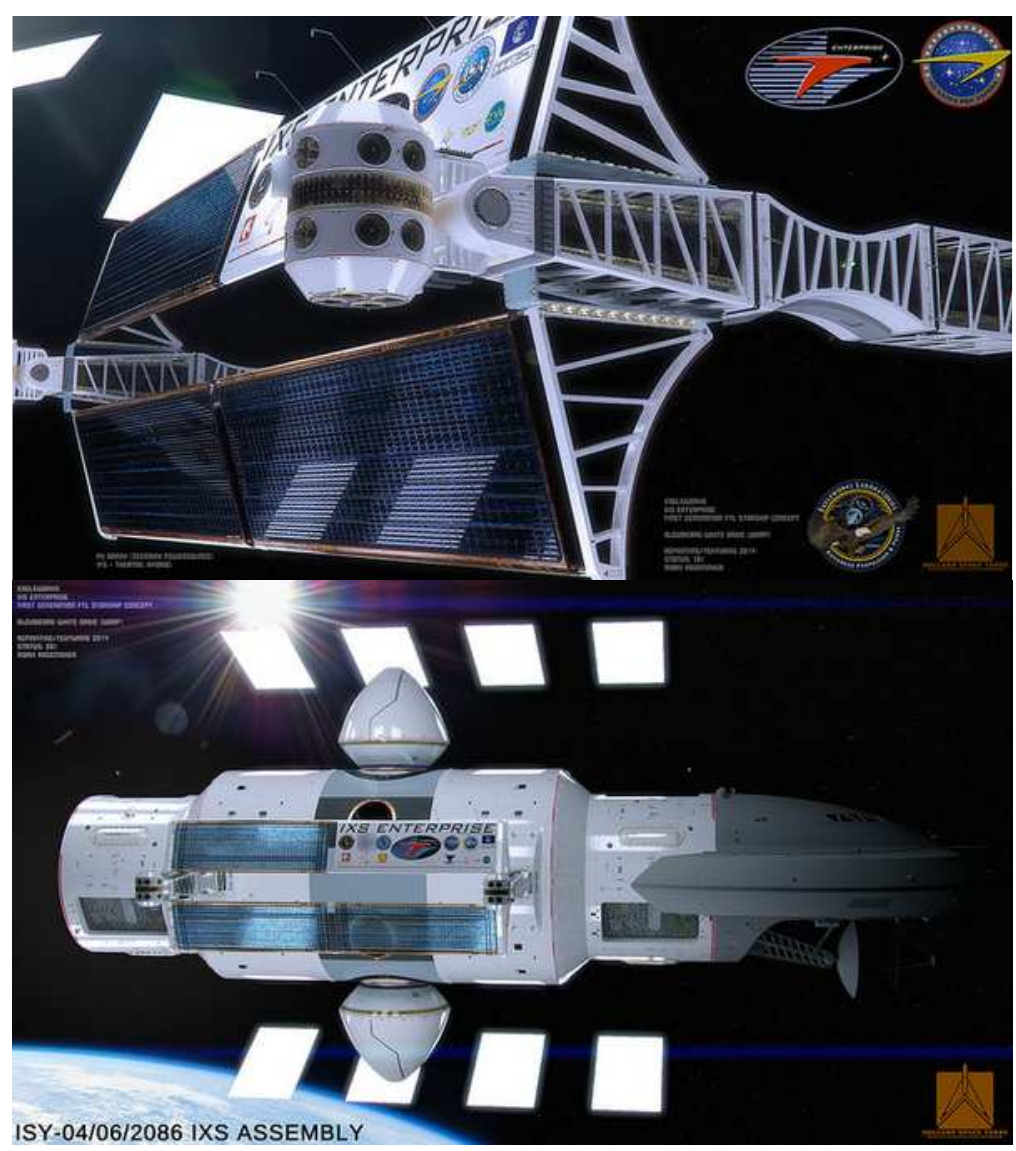

Fig. 1: A spacecraft equipped with a "warp" unit would allow moving at higher speeds than light by "bending" the space around it

If this experiment had the results that NASA experts want, White could create a motor that will take us to the Alpha Centauri star in two weeks.

"Time will be the same in the spacecraft as on Earth," says the researcher.

The authors propose the construction of modern, fast vessels, which can easily reach huge speeds, close to that of light, using laser propulsion (Petrescu and Petrescu, 2011a; 2012b; 2013c; Petrescu, 2009). In the future, circular particle accelerators mounted directly on ships could also be used.

\section{Discussion}

The main problem that has kept mankind for so many millennia has been the less speed of movement, but also the difficult exit into outer space. For a ship to be able to defeat gravitational forces and go out into outer space, leaving the planet and the earth's atmosphere and to place itself in orbit, the required minimum travel speed is about $28,476 \mathrm{~km} / \mathrm{h}$. In order to leave and the Earth orbit on which a ship is moving like a satellite, a ship needs a minimum speed of $40000 \mathrm{~km} / \mathrm{h}$. For a long time, such a speed was very difficult to achieve. Even with a huge amount of chemical fuel on board, a rocket had to throw a lot of rocket stages (modules) in an attempt to get out of the ground. Besides the huge fuel consumption (not to mention the huge pollution produced), the ship also encounters various technical difficulties, which most often cause it to abandon and return (the bathtub) and to the ground. The shuttle has attempted to modify something from this difficult start, coming out of the atmosphere, gradually planted, like a plane and not upright like a rocket. They, therefore, had the advantage of a lower mass, lower fuel consumption and resistance to advancing by making them more similar to planes. In addition, such a ship could emerge and return to the terrestrial space several times and not just as the missiles did. The shuttle was a step forward for humanity, even though it was still moving slowly. Then came the ions (gas) reactors for spatial ships, which managed to accelerate ships at increasing speeds. Of all spacecraft that were launched by humans, there were some that had an impressive speed. The current record is owned by the New Horizons mission to Pluto and the Kuiper belt. Launched in 2006 by NASA, the spacecraft had a speed of 58,536 kilometers per hour, but it has reached over 
160,000 kilometers per hour on its route. For comparison, Voyager 1 currently has a speed of 61,200 kilometers per hour. Regarding pure heliocentric speed, speed recorders are the Helios I and II probes, which were launched in 1974 and 1976 and reached speeds of 252,000 kilometers per hour. The Juno mission to Jupiter will send a spacecraft that will reach the speed of over 250,000 kilometers per hour. And in 2018, a new NASA mission called Solar Probe Plus will launch a ship that will travel at an astonishing speed of 720,000 kilometers per hour. This would mean the probe could travel from Earth to the Moon in about half an hour and the EarthMars distance in about 10 days instead of five months.

The Orion project was a study of a spacecraft to be propelled directly by a series of atom bomb explosions behind the ship (nuclear pulse propulsion). Initial versions of this vehicle have been proposed for launch from the ground, with significant decreases in radioactive nuclear waste; in the latest most recent versions have been developed to be used only in outer space.

Teleportation is a process of moving an object from one place to another, more or less instantaneously, without the object going through the space between the two positions. Several methods of teleportation (spacetime holes, wormholes) have been theoretically invented, but experimentally only quantum and psychic teleportation have been confirmed.

\section{Conclusion}

Space-time distortion. According to the theory of general relativity, space-time is curved. In science fiction, one can imagine using a "shortcut" between two points. The following formula based on general relativity can allow faster travel than light if space-time is curved.

In 2012, NASA physicist Harold White revealed that he and his team are working on the design of a spacecraft to travel at a speed higher than that of light.

Now, White has worked with an artist to create a new and more realistic design of the ship, writes Gizmodo.

In order to reach such speeds, the ship should have strong propulsion like ion or plasma. These propulsion systems have been called SF warp units.

A spacecraft equipped with a "warp" unit would allow moving at higher speeds than light by "bending" the space around it, thus reducing distances.

If this experiment had the results that NASA experts want, White could create a motor that will take us to the Alpha Centauri star in two weeks.

"Time will be the same in the spacecraft as on Earth," says the researcher.

The authors propose the construction of modern, fast vessels, which can easily reach huge speeds, close to that of light, using laser propulsion (Petrescu and Petrescu, 2011a; 2012b; 2013c; Petrescu, 2009). In the future, circular particle accelerators mounted directly on ships could also be used.

\section{Acknowledgement}

We acknowledge and thank Mr Taher M. AbuLebdeh, Associate Prof at North Carolina A and T State Univesity, United States and Mr Muftah H. El-Naas PhD MCIC FICCE QAFCO Chair Professor in Chemical Process Engineering Gas Processing Center College of Engineering Qatar University and Ms Shweta Agarwala, Senior Research Scientist at Singapore Center for 3D Printing Nanyang Technological University Singapore for their suggestions and comments.

\section{Funding Information}

Research contract: Contract number 36-5-4D/1986 from 24IV1985, beneficiary CNST RO (Romanian National Center for Science and Technology) Improving dynamic mechanisms internal combustion engines. All these matters are copyrighted. Copyrights: 548cgiywDssin, from: 22-04-2010, 08:48:48.

\section{Author's Contributions}

All the authors contributed equally to prepare, develop and carry out this manuscript.

\section{Ethics}

This article is original and contains unpublished material. The corresponding author confirms that all of the other authors have read and approved the manuscript and no ethical issues involved.

\section{References}

Aversa, R., D. Parcesepe, R.V. Petrescu, G. Chen and F.I.T. Petrescu et al., 2016b. Glassy amorphous metal injection molded induced morphological defects. Am. J. Applied Sci., 13: 1476-1482.

DOI: 10.3844/ajassp.2016.1476.1482

Aversa, R., D. Parcesepe, R.V.V. Petrescu, F. Berto and G. Chen et al., 2017d. Process ability of bulk metallic glasses. Am. J. Applied Sci., 14: 294-301. DOI: 10.3844/ajassp.2017.294.301

Aversa, R., E.M. Buzea, R.V. Petrescu, A. Apicella and M. Neacsa et al., 2016e. Present a mechatronic system having able to determine the concentration of carotenoids. Am. J. Eng. Applied Sci., 9: 1106-1111. DOI: 10.3844/ajeassp.2016.1106.1111

Aversa, R., F. Tamburrino, R.V. Petrescu, F.I.T. Petrescu and M. Artur et al., 2016d. Biomechanically inspired shape memory effect machines driven by muscle like acting NiTi alloys. Am. J. Applied Sci., 13: 1264-1271. DOI: 10.3844/ajassp.2016.1264.1271 
Aversa, R., F.I.T. Petrescu, R.V. Petrescu and A. Apicella, 2016a. Biomimetic FEA bone modeling for customized hybrid biological prostheses development. Am. J. Applied Sci., 13: 1060-1067. DOI: 10.3844/ajassp.2016.1060.1067

Aversa, R., F.I.T. Petrescu, R.V. Petrescu and A. Apicella, 2016o. Flexible stem trabecular prostheses. Am. J. Eng. Applied Sci., 9: 1213-1221. DOI: 10.3844/ajeassp.2016.1213.1221

Aversa, R., R.V. Petrescu, A. Apicella and F.I.T. Petrescu, 2016i. Mitochondria are naturally micro robots-a review. Am. J. Eng. Applied Sci., 9: 991-1002. DOI: 10.3844/ajeassp.2016.991.1002

Aversa, R., R.V. Petrescu, A. Apicella and F.I.T. Petrescu, 2016j. We are addicted to vitamins $\mathrm{C}$ and E-A review. Am. J. Eng. Applied Sci., 9: 1003-1018. DOI: 10.3844 /ajeassp.2016.1003.1018

Aversa, R., R.V. Petrescu, A. Apicella and F.I.T. Petrescu, 2016k. Physiologic human fluids and swelling behavior of hydrophilic biocompatible hybrid ceramo-polymeric materials. Am. J. Eng. Applied Sci., 9: 962-972.

DOI: 10.3844/ajeassp.2016.962.972

Aversa, R., R.V. Petrescu, A. Apicella and F.I.T. Petrescu, 20161. One can slow down the aging through antioxidants. Am. J. Eng. Applied Sci., 9: 1112-1126. DOI: 10.3844/ajeassp.2016.1112.1126

Aversa, R., R.V. Petrescu, A. Apicella and F.I.T. Petrescu, $2016 \mathrm{~m}$. About homeopathy or «Similia similibus curentur 》. Am. J. Eng. Applied Sci., 9: 1164-1172. DOI: 10.3844/ajeassp.2016.1164.1172

Aversa, R., R.V. Petrescu, A. Apicella and F.I.T. Petrescu, 2016n. The basic elements of life's. Am. J. Eng. Applied Sci., 9: 1189-1197. DOI: 10.3844/ajeassp.2016.1189.1197

Aversa, R., R.V. Petrescu, A. Apicella, I.T.F. Petrescu and J.K. Calautit et al., 2017c. Something about the $\mathrm{V}$ engines design. Am. J. Applied Sci., 14: 34-52. DOI: 10.3844/ajassp.2017.34.52

Aversa, R., R.V. Petrescu, B. Akash, R.B. Bucinell and J.M. Corchado et al., 2017b. Kinematics and forces to a new model forging manipulator. Am. J. Applied Sci., 14: 60-80. DOI: 10.3844/ajassp.2017.60.80

Aversa, R., R.V. Petrescu, F.I.T. Petrescu and A. Apicella, 2016c. Smart-factory: Optimization and process control of composite centrifuged pipes. Am. J. Applied Sci., 13: 1330-1341. DOI: 10.3844/ajassp.2016.1330.1341

Aversa, R., R.V. Petrescu, F.I.T. Petrescu and A. Apicella, 2016h. Biomimetic and evolutionary design driven innovation in sustainable products development. Am. J. Eng. Applied Sci., 9: 1027-1036. DOI: 10.3844/ajeassp.2016.1027.1036

Aversa, R., R.V. Petrescu, R. Sorrentino, F.I.T. Petrescu and A. Apicella, 2016f. Hybrid ceramo-polymeric nanocomposite for biomimetic scaffolds design and preparation. Am. J. Eng. Applied Sci., 9: 1096-1105. DOI: 10.3844/ajeassp.2016.1096.1105
Aversa, R., R.V.V. Petrescu, A. Apicella and F.I.T. Petrescu, 2017a. Nano-diamond hybrid materials for structural biomedical application. Am. J. Biochem. Biotechnol., 13: 34-41. DOI: $10.3844 /$ ajbbsp.2017.34.41

Aversa, R., R.V.V. Petrescu, B. Akash, R.B. Bucinell and J.M. Corchado et al., 2017e. Something about the balancing of thermal motors. Am. J. Eng. Applied Sci., 10: 200.217. DOI: 10.3844/ajeassp.2017.200.217

Aversa, R., V. Perrotta, R.V. Petrescu, C. Misiano and F.I.T. Petrescu et al., 2016g. From structural colors to super-hydrophobicity and achromatic transparent protective coatings: Ion plating plasma assisted $\mathrm{TiO} 2$ and SiO2 Nano-film deposition. Am. J. Eng. Applied Sci., 9: 1037-1045. DOI: 10.3844/ajeassp.2016.1037.1045

Berto, F., A. Gagani, R. Aversa, R.V.V. Petrescu and A. Apicella et al., 2016d. Multiaxial fatigue strength to notched specimens made of 40CrMoV13.9. Am. J. Eng. Applied Sci., 9: 1269-1291.

Berto, F., A. Gagani, R.V.V. Petrescu and F.I.T. Petrescu, 2016c. Key-hole notches in isostatic graphite: A review of some recent data. Am. J. Eng. Applied Sci., 9: 1292-1300.

Berto, F., R.V.V. Petrescu and F.I.T. Petrescu, 2016a. A review of recent results on $3 \mathrm{D}$ effects. Am. J. Eng. Applied Sci., 9:1247-1260.

Berto, F., R.V.V. Petrescu and F.I.T. Petrescu, $2016 \mathrm{~b}$. Three-dimensional in bonded joints: A short review. Am. J. Eng. Applied Sci., 9:1261-1268.

Mirsayar, M.M., V.A. Joneidi, R.V.V. Petrescu, F.I.T. Petrescu and F. Berto, 2017. Extended MTSN criterion for fracture analysis of soda lime glass. Eng. Fracture Mechanics, 178: 50-59. DOI: $10.1016 /$ j.engfracmech.2017.04.018

Petrescu, F.I. and J.K. Calautit, 2016b. About the light dimensions. Am. J. Applied Sci., 13:321-325. DOI: 10.3844/ajassp.2016.321.325

Petrescu, F.I. and R.V. Petrescu, 2011 a. Memories about Flight. 1st Edn., CreateSpace, pp: 652.

Petrescu, F.I. and R.V. Petrescu, 2011b. Mechanical Systems, Serial and Parallel.1st Edn., lulu.com Publisher, London, UK. ISBN-10: 1446600394, pp: 124.

Petrescu, F.I. and R.V. Petrescu, 2012b. New Aircraft II. 1st Edn., Books on Demand, pp: 138.

Petrescu, F.I. and R.V. Petrescu, 2012c. MecatronicaSisteme Seriale Si Paralele. 1st Edn., Create Space Publisher, USA, ISBN-13: 978-1-4750-6613-5, pp: 128.

Petrescu, F.I. and R.V. Petrescu, 2012d. Kinematics of the planar quadrilateral mechanism. Engevista, 14: 345-348.

Petrescu, F.I. and R.V. Petrescu, 2013d. Cinematics of the 3R Dyad. Engevista, 15: 118-124. 
Petrescu, F.I. and R.V. Petrescu, 2016a. Parallel moving mechanical systems kinematics. ENGE-VISTA, 18:455-491.

Petrescu, F.I. and R.V. Petrescu, 2016b. Direct and inverse kinematics to the anthropomorphic robots. ENGEVISTA, 18: 109-124.

Petrescu, F.I. and R.V. Petrescu, 2016c. Dynamic cinematic to a structure 2R. Revista Geintec-Gestao Inovacao E Tecnologias, 6: 3143-3154.

Petrescu, F.I.T. and J.K. Calautit, 2016a. About nano fusion and dynamic fusion. Am. J. Applied Sci., 13: 261-266.

Petrescu, F.I.T., 2009. New aircraft. Proceedings of the 3rd International Conference on Computational Mechanics, Oct. 29-30, Brasov, Romania.

Petrescu, F.I.T., 2012a. Cold Nuclear Fusion. 1st Edn., Create Space, USA, ISBN-10: 1478234261, pp: 80.

Petrescu, F.I.T., 2012b. Particle Annihilation - a Source of Renewable Energy? Infinite Energy Magazine, LuLu Publishers, USA.

Petrescu, F.I.T., 2016. Valorificarea Traditiei Ingineresti Romanesti-I: Create Space Publisher, USA. 1st Edn., CreateSpace Independent Publishing Platform, ISBN-10: 1536889946, pp: 152.

Petrescu, F.I.T., A. Apicella, R.V.V. Petrescu, S.P. Kozaitis and R.B. Bucinell et al., 2016b. Environmental protection through nuclear energy. Am. J. Applied Sci., 13:941-946.

Petrescu, R.V. and F.I. Petrescu, 2013a. Lockheed Martin. 1st Edn., CreateSpace, pp: 114.

Petrescu, R.V. and F.I. Petrescu, 2013b. Northrop. 1st Edn., CreateSpace, pp: 96.

Petrescu, R.V. and F.I. Petrescu, 2013c. The Aviation History or New Aircraft I Color. 1st Edn., CreateSpace, pp: 292.
Petrescu, R.V. and F.I.T. Petrescu, 2012a. Northrop. 1st Edn., Books on Demand, ISBN-10: 3848209322, pp: 142.

Petrescu, R.V., R. Aversa, A. Apicella and F.I. Petrescu, 2016c. Future medicine services robotics. Am. J. Eng. Applied Sci., 9: 1062-1087.

Petrescu, R.V.V., R. Aversa, A. Apicella, F. Berto and S. Li et al., 2016a. Ecosphere protection through green energy. Am. J. Applied Sci., 13: 1027-1032.

Rincon, P., 2004. Teleportation breakthrough made. BBC News.

http://news.bbc.co.uk/2/hi/science/nature/3811785.stm

Science \& Space, 2006. Scientists teleport two different objects. Science \& Space, Time Warner Company, United States.

Sherson, J.F., H. Krauter, RK. Olsson, B. Julsgaard and K. Hammerer et al., 2006. Quantum teleportation between light and matter. Nature, 443: 557-560. DOI: 10.1038 /nature 05136

Teleportare, De la Wikipedia. Enciclopedia liberă. https://ro.wikipedia.org/wiki/Teleportare.

The Sydney Morning Herald, 2006. Danish researchers boldly go where none have gone before 2006. The Sydney Morning Herald, Fairfax Digital, Australia.

\section{Source of Figures}

http://www.gandul.info/magazin/conceptul-primei-navespatiale-mai-rapide-decat-lumina-galerie-foto-12769633 